\title{
Reciprocal Immunological Distances of Catalase Derived from Strains of Mycobacterium avium, Mycobacterium tuberculosis, and Closely Related Species
}

\author{
LAWRENCE G. WAYNE ${ }^{1,2}$ AND GILBERT A. DIAZ ${ }^{1}$ \\ Tuberculosis Research Laboratory, Veterans Administration Hospital, Long Beach, California 90822, ${ }^{1}$ and \\ Department of Medical Microbiology, California College of Medicine, University of California, Irvine, \\ California $92664^{2}$
}

\begin{abstract}
The structural divergence of catalase derived from different mycobacteria has previously been studied in terms of immunological distances as determined by titration with antiserum against catalase extracted from Mycobacterium tuberculosis. This study has been extended by addition of a second reference antiserum: one raised against catalase from $M$. avium. The two systems show a high reciprocality of immunological distance against one another. The catalase from $M$. intracellulare is serologically very similar to that of $M$. avium, and the enzyme from $M$. bovis is very similar to that of $M$. tuberculosis. Catalase extracted from BCG, a pathovar of $M$. bovis, appears to exhibit structural modification which diverges from the parent $M$. bovis and converges on $M$. avium. Two classes of catalase have been separated from $M$. scrofulaceum: one is nonreactive with either reference antiserum, and the other exhibits immunological distances that suggest that $M$. avium is in a position between $M$. scrofulaceum and $M$. tuberculosis.
\end{abstract}

Two classes of catalase have been detected in different mycobacteria. They differ from one another in terms of susceptibility to heat (5) and to inhibitors (1). One of these classes, which is the only one found in Mycobacterium tuberculosis, is rapidly inactivated at $53^{\circ} \mathrm{C}(4)$ and appears to be associated with susceptibility of the cells to isoniazid. Antibody to catalase from $M$. tuberculosis has been found to cross-react with the heat-labile catalase extracted from a number of other mycobacterial species, and its relative binding capacity to these products has provided a basis for estimating the structural divergence of these closely related isozymes (12). To assess further the utility of this method for studying evolutionary pathways in the genus Mycobacterium, reciprocal studies have been carried out between antibodies prepared against catalase from $M$. tuberculosis and from M. avium, both of which belong to the heat-labile class. Strains of species closely related to $M$. tuberculosis (i.e., $M$. bovis and $M$. africanum) and to $M$. avium (i.e., $M$. intracellulare and $M$. scrofulaceum) have been included to aid in assessment of the range of immunological distances (ImD's) encompassed by a species.

\section{MATERIALS AND METHODS}

Bacterial strains. Catalase was extracted from 20 strains of mycobacteria. The reference catalase for $M$. tuberculosis $\mathrm{H}_{37} \mathrm{Rv}$ was derived from our stock labo- ratory culture, designated W-196. Four recently isolated wild strains of M. tuberculosis, designated by Knumbers, were provided by the Veterans Administration Special Reference Laboratory for Tuberculosis and Other Mycobacterial Diseases, Long Beach, Calif. Two strains of M. africanum, designated TC20 and TC37, were received from $\mathrm{H}$. H. Kleeberg, Tuberculosis Research Institute, Pretoria, South Africa. The balance of the cultures employed were provided by $M$. Lefford of the Trudeau Mycobacterial Culture Collection (TMC), Saranac Lake, N.Y. (11). M. avium TMC 716 , serotype 1 , was used to prepare the $M$. avium reference catalase.

Preparation of catalase. The methods used to produce catalase were modified slightly from those presented in prior reports $(4,12)$. The cells were inoculated into 500-ml baffled nephelo flasks (Bellco, Vineland, N.J.) containing $200 \mathrm{ml}$ of TB broth base (Difco Laboratories, Detroit, Mich.) enriched with Dubos medium albumin (Difco) plus $0.75 \%$ glycerol. This medium has been found to prevent the inhibitory effect of continuous shaking on some mycobacteria (10). The cultures were incubated at $37^{\circ} \mathrm{C}$ without agitation for the first 7 days, i.e., until turbidity was evident. They were then further incubated at $37^{\circ} \mathrm{C}$ with rotary agitation $(115 \mathrm{rpm})$ on a Psycrotherm incubator shaker (New Brunswick Scientific Co., New Brunswick, N.J.) for an additional 7 to 14 days. The optical absorbance at $580 \mathrm{~nm}$ was monitored, and the cultures were harvested when it corresponded to a cell concentration of 10 to $20 \mathrm{mg}$ (moist weight) per ml. The cultures were centrifuged for $30 \mathrm{~min}$ at $4,300 \times g$ and the supernatants were discarded. The cells were suspended in $1 / 4$ of the original culture volume 
of $0.005 \mathrm{M}$ tris(hydroxymethyl)aminomethane-phosphate load buffer ( $\mathrm{pH} 8.0$ ), transferred to calibrated centrifuge tubes, and centrifuged again. The supernatants were discarded, the volume of packed cells was noted, and the cells were suspended in an equal volume of load buffer and disrupted by sonic oscillation as described previously (4).

Sonic extracts were added to a suspension of diethylaminoethyl (DEAE)-cellulose (Sigma Chemical Co., St. Louis, Mo.), containing $500 \mathrm{mg}$ of DEAE per $\mathrm{ml}$ of packed cells as measured before sonic treatment, in $100 \mathrm{ml}$ of cold load buffer. After mixing, the DEAEcellulose with adsorbed cellular proteins was permitted to settle at $5^{\circ} \mathrm{C}$. The cloudy, lipid-rich supernatant was discarded. The DEAE-cellulose was washed several times in cold load buffer until the supernatant was only slightly opalescent. The DEAE-cellulose was then resuspended in load buffer, transferred to a chromatographic column, and allowed to settle. The packed column was washed with more load buffer until the effluent was clear; the washes were discarded. The bound protein was eluted with $0.5 \mathrm{M} \mathrm{NaCl}$ buffer (equal portions of load buffer and $1 \mathrm{M} \mathrm{NaCl}$ in $0.05 \mathrm{M}$ phosphate, $\mathrm{pH} 6.5$ ); $30 \mathrm{ml}$ of the buffer mixture was used per gram of DEAE-cellulose. The eluate was sterilized by membrane (Millipore Corp., Bedford, Mass.) filtration. Ammonium sulfate was added to $70 \%$ saturation, and the protein precipitate was collected, dissolved in a small volume of $0.1 \mathrm{M}$ phosphate buffer (pH 7.5), and dialyzed against more of the same buffer. A sample of this crude protein extract (CPE) was assayed for catalase activity and diluted in buffer to the desired concentration. The CPE preparations were used in the immunological assays.

To prepare purified catalase for immunization of rabbits, sonic extracts of $M$. tuberculosis W-196 and $M$. avium TMC 716 were further fractionated by ammonium sulfate precipitation, DEAE-cellulose chromatography, and Sephadex chromatography as described previously (4). For reasons discussed in the Results, a batch of $M$. scrofulaceum TMC 1314 sonic extract was also fractionated.

Preparation of antisera. The rabbit antiserum against catalase from $M$. tuberculosis W-196 was prepared as described previously (12). For preparation of $M$. avium TMC 716 catalase antiserum, New Zealand white rabbits were injected intravenously with $0.5 \mathrm{ml}$ of a buffered solution containing $40 \mu \mathrm{g}$ of the purified catalase. Five and nine weeks later they received intradermally $0.05 \mathrm{ml}$ of incomplete Freund adjuvant (Difco) containing $40 \mu \mathrm{g}$ of catalase protein. Five weeks later they received intravenously $10 \mu \mathrm{g}$ of catalase in $0.05 \mathrm{ml}$ of buffer; 2 weeks after that, the serum was harvested. The $M$. avium antiserum contained excessive intrinsic peroxide-destroying activity, so it was necessary to separate the immunoglobulin by ammonium sulfate precipitation and DEAE-cellulose absorption (6).

Serological titrations. In our prior study the reaction products of catalase and antibody were diluted and centrifuged, and the supernatants were reconcentrated by ultrafiltration for assay of residual catalase. By employing a microcentrifuge (Microfuge B, Beckman Instruments, Inc., Palo Alto, Calif.), it was possible to eliminate these cumbersome steps. Serial di- lutions of serum were prepared, and $100 \mu$ l of each was dispensed into $400-\mu \mathrm{l}$ polyethylene centrifuge tubes. To each was added two titration units of the appropriate purified catalase of CPE in $100 \mu \mathrm{l}$ of a $2-\mathrm{mg} / \mathrm{ml}$ solution of bovine serum albumin in $0.1 \mathrm{M}$ phosphate buffer ( $\mathrm{pH} 7.5$ ). One titration unit is defined as that amount of mycobacterial catalase that will destroy $1.84 \mu \mathrm{mol}$ of $\mathrm{H}_{2} \mathrm{O}_{2}$ in $5 \mathrm{~min}$ under conditions of the zero-order assay described in our prior report (12). After the contents of the tubes were mixed by inversion and shaking followed by $30 \mathrm{~s}$ of centrifugation to eliminate bubbles, the mixtures were incubated at $37^{\circ} \mathrm{C}$ for $1 \mathrm{~h}$ and then permitted to stand at $5^{\circ} \mathrm{C}$ overnight. They were then centrifuged for $5 \mathrm{~min}$ in the Microfuge B, and $100 \mu \mathrm{l}$ of supernatant was removed for assay of residual catalase by the zero-order assay. The proportions of catalase lost were plotted on probability paper against the logs of the dilutions of serum, and the log dilution of the intercept corresponding to removal of 0.5 titration unit from $100 \mu \mathrm{l}$ of supernatant was recorded. The binding capacity of a serum against a given catalase preparation is the reciprocal of that dilution of serum which will precipitate 0.5 titration unit of catalase under conditions of this titration. The $\mathrm{ImD}$ between reference and a heterologous catalase preparation is defined as $100\left(\log B_{h}-\log B_{t}\right)$, where $B_{h}$ is the binding capacity of the reference serum against the homologous reference catalase and $B_{t}$ is the binding capacity of that same serum against the heterologous catalase $(9,12)$. The $\operatorname{ImD}$ correlates well with structural divergence of proteins, up to substitution of about $40 \%$ of the amino acids $(3,9)$.

\section{RESULTS}

The mean homologous binding capacities of the two reference antisera against purified catalase from M. tuberculosis W-196 and M. avium TMC 716 were 543 and 28 , respectively. The low titer of the $M$. avium globulin represented the best from three rabbits. To use it at very low dilutions for assay of heterologous organisms, it had been necessary to purify the globulin as described and thus eliminate interference from intrinsic peroxide-destroying substances. It was possible to precipitate the catalase activity from all but one CPE by using low enough dilutions of reference sera. The single exception was a CPE prepared from $M$. scrofulaceum TMC 1314, which gave no evidence of reaction with either serum. When this crude enzyme product was subjected to gradient salt DEAE-cellulose chromatography (4), two overlapping catalase peaks were seen. When distal fractions of the two peaks were titrated, one failed to react with either reference serum, but the other reacted with both. The serological reactivity in the original unfractionated mixture had been masked by the dominant, serologically nonreactive component. The existence of both classes of catalase in some species has since been noted repeatedly; further studies of these products are under way and will be reported at a later date. The serologically 
reactive fraction of $M$. scrofulaceum catalase was included in the present study.

The stability of the catalase from TMC 715, TMC 1403, and TMC 1405 was examined by storing their CPEs, adjusted to contain 20 titration units of activity per $\mathrm{ml}$, under several conditions. After storage for 8 weeks, the mean retention of activity was $99.8 \%$ at $-70^{\circ} \mathrm{C}, 95.7 \%$ at $5^{\circ} \mathrm{C}$ with a crystal of thymol added as a preservative, and $96.6 \%$ at $5^{\circ} \mathrm{C}$ with no preservative. It was elected to store all working samples at $5^{\circ} \mathrm{C}$ with thymol. Samples of reference $M$. tuberculosis catalase have since been kept under these conditions for a year or more without loss of activity. Furthermore, a freshly prepared crude catalase CPE preparation from $M$. tuberculosis W-196 was titrated in parallel with a 41 month-old preparation of purified catalase from the same strain. The ImD between the two was only $0.2 \pm 1.8$, i.e., well within the limits of variability of the technique. Nevertheless, since the crude protein samples for serological analysis are standardized according to their enzymatic activity, not total protein content, experiments were undertaken to determine whether inactivated enzyme could still bind antibody and thus interfere with an accurate assessment of binding capacity. Several concentrated samples of catalase derived from wild strains of $M$. tuberculosis were observed to lose some enzyme activity on prolonged storage. They were diluted to appropriate concentrations, based on observed activity, and titrated against dilutions of the $M$. $t u$ berculosis reference antiserum. The observed activity was recorded in terms of apparent ImD, as compared with the original freshly prepared enzymes (Table 1). Assuming that the original product represented enzyme with $100 \%$ activity, the ImD for each partially inactivated product was also predicted as if inactive enzyme were able to compete directly for antibody sites with

TABLE 1. Changes in apparent immunological distances of some $M$. tuberculosis CPE catalase preparations that exhibited a partial loss of enzyme activity on prolonged storage

\begin{tabular}{|c|c|c|c|c|}
\hline \multirow{2}{*}{ Prep } & \multirow{2}{*}{$\begin{array}{c}\text { Age } \\
\text { (months) }\end{array}$} & \multirow{2}{*}{$\begin{array}{c}\text { Inactivation } \\
(\%)\end{array}$} & \multicolumn{2}{|c|}{$\Delta \operatorname{ImD} D^{a}$} \\
\hline & & & Predicted & Observed \\
\hline $\mathbf{A}$ & 0 & 0 & 0 & \\
\hline $\mathbf{A}$ & 21 & 74 & 59 & 24 \\
\hline $\mathbf{A}$ & 35 & 77 & 64 & 29 \\
\hline $\mathbf{B}$ & 0 & 0 & 0 & \\
\hline B & 21 & 66 & 47 & 25 \\
\hline B & 35 & 77 & 64 & 29 \\
\hline $\mathrm{C}$ & 0 & 0 & 0 & \\
\hline C & 13 & 31 & 16 & 13 \\
\hline
\end{tabular}

${ }^{a} \Delta \operatorname{ImD}$, Change in apparent $\operatorname{ImD}$ from the $M$. tuberculosis reference system. active enzyme. It is evident that there is a degree of serological competition from catalase that has lost some enzymatic activity on prolonged storage. The observed changes in $\mathrm{ImD}$ are, on the average, only about half of those predicted if inactive enzyme were fully competitive. Since the serological studies reported in Table 2 are based on preparations that were at the same level of activity when tested against both reference sera, competition may have had a slight influence on observed ImD's, but much less of an effect on reciprocal values for species very closely related to one of the reference systems (see discussion of adjusted differences below). When a sample of $M$. tuberculosis W-196 catalase that had been completely inactivated by treatment at $55^{\circ} \mathrm{C}$ for $6 \mathrm{~min}$ was mixed in the proportion of three parts of inactive enzyme to one part of fully active enzyme, no shift in apparent ImD was seen; i.e., the serologically active determinants of the molecule were as susceptible to denaturation by heat as was the enzymatic determinant. A similar experiment was designed in which inactivation was attempted by vigorous aeration, accompanied by foaming, at room temperature. After $2 \mathrm{~h}$ of such treatment there was no evidence of loss of enzyme activity due to protein denaturation at the foam interfaces.

The ImD's of the catalases tested against the two reference antisera are based on an average of three replications per strain (Table 2). The ImD of $M$. tuberculosis W-196 reference catalase against anti- $M$. avium serum was 97.1 , and that of the reciprocal assay of $M$. avium TMC 716 reference catalase against anti- $M$. tuberculosis serum was 98.1 , a very high order of agreement. The mean ImD of the strains of $M$. tuberculosis against the homologous species antiserum was -5.0 , and that of the two strains of $M$. avium against homologous species antiserum was -4.3 . A negative value suggests that there could have been traces of competing, enzymatically inactive catalase in the two reference preparations. The mean ImD of the six $M$. tuberculosis strains against the $M$. tuberculosis antiserum is significantly different from that of the two $M$. bovis strains $(P<0.05)$, the six $M$. bovis BCG strains $(P<0.005)$, and the two $M$. africanum strains $(P<0.025)$. Similarly, the difference between ImD's of the $M$. avium strains and the $M$. intracellulare strains against the $M$. avium antiserum is significant $(P<0.025)$. If the two strains each of $M$. avium and $M$. intracellulare are combined as a single entity for comparison with the single strain of $M$. scrofulaceum, the ImD of the latter against the $M$. avium antiserum is significantly greater $(P<0.01)$ than the mean of the former.

As a further test of reciprocality of the two 
TABLE 2. Immunological distances and adjusted differences for mycobacterial catalase tested against two reference systems

\begin{tabular}{|c|c|c|c|c|c|c|c|c|}
\hline \multirow{3}{*}{ Organism } & \multirow{3}{*}{ Strain } & \multirow{3}{*}{$\begin{array}{l}\text { Source or } \\
\text { serotype }^{a}\end{array}$} & \multicolumn{4}{|c|}{ Reference system } & \multicolumn{2}{|c|}{ Adjusted differences } \\
\hline & & & \multicolumn{2}{|c|}{$\begin{array}{c}\text { M. tuberculosis } \\
\text { W-196 }\end{array}$} & \multicolumn{2}{|c|}{$\begin{array}{l}\text { M. avium } \\
\text { TMC } 716\end{array}$} & \multirow{2}{*}{$D_{r}-D_{N}{ }^{b}$} & \multirow{2}{*}{$\begin{array}{l}\text { Standard } \\
\text { deviation }\end{array}$} \\
\hline & & & $\operatorname{ImD}$ & $\begin{array}{l}\text { Standard } \\
\text { deviation }\end{array}$ & $\operatorname{ImD}$ & $\begin{array}{l}\text { Standard } \\
\text { deviation }\end{array}$ & & \\
\hline \multirow[t]{2}{*}{$\begin{array}{l}\text { M. tuberculo- } \\
\quad \text { sis }\end{array}$} & $\begin{array}{l}\text { W-196 } \\
\text { K-5184 } \\
\text { K-9767 } \\
\text { K-9775 } \\
\text { K-9784 }\end{array}$ & & $\begin{array}{c}(0) \\
-1.9 \\
-1.4 \\
-9.4 \\
-12.2 \\
\end{array}$ & $\begin{array}{c}( \pm 8.7)^{c} \\
\pm 6.8 \\
\pm 6.0 \\
\pm 6.8 \\
\pm 7.6 \\
\end{array}$ & $\begin{array}{l}97.1 \\
\mathrm{ND}^{\alpha} \\
92.3 \\
83.7 \\
\mathrm{ND} \\
\end{array}$ & $\begin{array}{l} \pm 5.0 \\
\pm 0.1 \\
\pm 4.7\end{array}$ & $\begin{array}{l}97.1 \\
\\
93.7 \\
93.1\end{array}$ & \\
\hline & & & $-5.0^{e}$ & \pm 5.4 & 91.0 & \pm 6.8 & 94.6 & \pm 2.2 \\
\hline \multirow[t]{2}{*}{ M. bovis } & $\begin{array}{l}\text { TMC-401 } \\
\text { TMC-407 }\end{array}$ & & $\begin{array}{l}2.0 \\
8.7\end{array}$ & $\begin{array}{l} \pm 8.2 \\
\pm 6.4\end{array}$ & $\begin{array}{l}94.6 \\
98.0 \\
\end{array}$ & $\begin{array}{l} \pm 0.5 \\
\pm 3.5 \\
\end{array}$ & $\begin{array}{l}92.6 \\
89.3 \\
\end{array}$ & \\
\hline & & & 5.4 & \pm 4.7 & $\overline{96.3}$ & \pm 2.4 & $\overline{91.0}$ & $\overline{ \pm 2.3}$ \\
\hline \multirow[t]{6}{*}{ M. bovis $\mathrm{BCG}$} & $\begin{array}{l}\text { TMC-1002 } \\
\text { TMC-1010 }\end{array}$ & $\begin{array}{c}\text { Albany } \\
\text { Copen- } \\
\text { hagen }\end{array}$ & $\begin{array}{l}11.5 \\
15.9\end{array}$ & $\begin{array}{l} \pm 9.5 \\
\pm 6.6\end{array}$ & $\begin{array}{l}80.2 \\
\mathrm{ND}\end{array}$ & \pm 7.4 & 68.7 & \\
\hline & TMC-1011 & Paris & -2.4 & \pm 3.0 & 64.4 & \pm 2.0 & 66.8 & \\
\hline & TMC-1019 & Tokyo & 25.2 & \pm 2.2 & 93.9 & \pm 2.6 & 68.7 & \\
\hline & TMC-1022 & Moscow & 19.1 & \pm 4.7 & ND & & & \\
\hline & TMC-1028 & Chicago & 3.9 & \pm 4.8 & ND & & & \\
\hline & & & 13.0 & \pm 8.9 & 79.5 & \pm 14.8 & 68.1 & \pm 1.1 \\
\hline \multirow[t]{2}{*}{ M. africanum } & $\begin{array}{l}\text { TC-20 } \\
\text { TC-37 }\end{array}$ & & $\begin{array}{l}2.8 \\
2.8 \\
\end{array}$ & $\begin{array}{l} \pm 1.3 \\
\pm 2.6\end{array}$ & $\begin{array}{l}\text { ND } \\
75.4 \\
\end{array}$ & \pm 3.8 & 72.6 & \\
\hline & & & 2.8 & & & & & \\
\hline \multirow[t]{3}{*}{ M. avium } & TMC-716 & 1 & 98.1 & \pm 6.2 & $(0)$ & $( \pm 3.4)^{c}$ & 98.1 & \\
\hline & TMC-715 & 2 & 107.4 & \pm 0.7 & -8.5 & \pm 6.2 & $\underline{115.9}$ & \\
\hline & & & 102.8 & \pm 6.6 & -4.3 & \pm 6.0 & 107.0 & \pm 12.6 \\
\hline \multirow[t]{2}{*}{$\begin{array}{l}\text { M. intracel- } \\
\text { lulare }\end{array}$} & $\begin{array}{l}\text { TMC-1403 } \\
\text { TMC-1405 }\end{array}$ & $\begin{array}{l}14 \\
12\end{array}$ & $\begin{array}{l}109.7 \\
108.7 \\
\end{array}$ & $\begin{array}{l} \pm 2.0 \\
\pm 9.3 \\
\end{array}$ & $\begin{array}{r}34.1 \\
3.8 \\
\end{array}$ & $\begin{array}{l} \pm 6.5 \\
\pm 9.6 \\
\end{array}$ & $\begin{array}{r}75.6 \\
104.9 \\
\end{array}$ & \\
\hline & & & 109.2 & \pm 0.7 & 19.0 & \pm 21.4 & 90.3 & \pm 20.7 \\
\hline $\begin{array}{l}\text { M. scrofula- } \\
\text { ceum }\end{array}$ & TMC-1314 & 41 & 187.0 & \pm 7.1 & 54.9 & \pm 5.4 & 132.1 & \\
\hline
\end{tabular}

${ }^{a}$ Source, as applied to BCG strains, refers to the laboratories in which they were maintained before accession in the Trudeau Collection (11); serotype numbers refer to $M$. avium complex designations (13).

${ }^{b} D_{F}$, Immunological distance from the most distant of the two reference systems; $D_{N}$, distance to the nearest one.

${ }^{c}$ Standard deviations of the two reference systems are based upon the mean homologous binding capacities.

${ }^{d} \mathrm{ND}$, Not determined.

Mean.

reference systems, an "adjusted difference" was calculated by subtracting the smaller mean distance recorded for each strain from the larger (Table 2). This calculation is based on the hypothesis that the "true" smaller mean distance is zero against one of the reference systems and that the variations are of a technical nature. The mean adjusted differences calculated for $M$. $t u$ berculosis, $M$. bovis, $M$. avium, and $M$. intracellulare were not significantly different from one another $(P>0.05)$, thus supporting recip- rocality at a mean combined reciprocal value for these four species of 95.6 and suggesting that a small degree of competition from inactive enzyme may have been a significant factor in their variability. A marked compression of standard deviation was seen with $M$. tuberculosis and, even more strikingly, with BCG. However, the mean adjusted difference for BCG strains (68.1) is significantly lower than the combined reciprocal values for the previously mentioned four species $(P<0.005)$. This appears to place BCG 
in an intermediate position between the two reference systems; i.e., the sum of the two mean observed ImD's is 92.5 , a value very close to the mean combined reciprocal values cited above. The very large standard deviations of the mean adjusted differences for $M$. avium and $M$. intracellulare suggest a greater heterogeneity among catalases from these species than among those from the $M$. tuberculosis/M.bovis complex. The mean adjusted difference for $M$. scrofulaceum is significantly greater than the combined reciprocal values cited above $(P<0.005)$, suggesting a significant departure from the proportionality of $\mathrm{ImD}$ and amino acid sequence in this species (8). The observed ImD scores indicate that $M$. avium falls between $M$. scrofulaceum and $M$. tuberculosis at some point on the line of structural divergence of the enzyme.

\section{DISCUSSION}

The addition of a second reference system for analysis of structural divergence of mycobacterial catalse has provided two advantages over the prior single-serum system. Reciprocality has been demonstrated, thus increasing confidence in the use of the serological measurement, and the relative positions of products with respect to one another may be estimated. Deviations from reciprocality have been suggested to be largely due to a nonproportional relationship between immunological distances and the number of amino acid differences in antigens from two species (8).

The structural divergence of catalase from strains of $M$. tuberculosis and strains of $M$. bovis is very small, with the raw mean ImD scores against the $M$. tuberculosis strains barely exceeding the standard deviations of the individual preparations. In light of these observations, the difference seen with the BCG strains merits comment. The sum of the mean of the recorded ImD values of BCG against $M$. tuberculosis strains (13.0) and $M$. avium strains (79.5) closely approximates the reciprocal scores of the two reference systems, thus supporting an intermediate position for BCG. The BCG pathovar was originally derived from a pathogenic strain of $M$. bovis by repeated passage on a bile-containing medium. The original strain of $M$. bovis is no longer available (H. David, personal communication), so it cannot be determined whether it was an anomolous strain. If it is assumed to have been a typical strain of $M$. bovis, then the apparent structural convergence of the BCG catalase toward $M$. avium may represent a response to the high selective pressure of the medium employed to derive this strain. The close agreement between adjusted differences of the three strains maintained independently in different laboratories (17 years in Albany, 59 years in Paris, and 52 years in Tokyo) before transmittal to the Trudeau Institute (11) suggests stability under less selective maintenance cultivation. Further experiments are planned to try to elucidate the specific nature of the selective pressure that may have contributed to the apparent structural convergence.

The calculation of adjusted differences (Table 2) led to a compression of standard deviations in the $M$. tuberculosis complex compared with those of the raw ImD scores. The opposite was true of the $M$. avium $/ M$. intracellulare complex, suggesting that raw ImD scores in this group reflect a more heterogeneous structural range. This difference is compatible with the ranges of habitats characteristic of these organisms. Although all of the species studied (except $M$. africanum) have a worldwide distribution, the specific habitats differ. Thus, $M$. tuberculosis and $M$. bovis are found only in the restrictive environment of mammalian tissue, and BCG is maintained on standardized media. $M$. avium and $M$. intracellulare, on the other hand, occupy such diverse habitats as fodder, soil, animal bedding, and avian and mammalian tissue and are presumably subject to a greater variety of selective pressures that could lead to evolution of small changes in catalase structure.

The correlation between evolutionary distance among species of higher organisms and the immunological distances of their proteins rests to some extent on an assumption that amino acid substitution follows a Poisson process (8). Whereas the occurrences of such substitutions in bacteria probably do follow a Poisson process, the conservation of substitutions in some enzymes is probably subjected to greater external environmental influence in a singlecelled organism than in a higher organism, the enzymes of which are protected in a more complex, homeostatic environment. The apparent convergence of the BCG catalase toward that of $M$. avium thus suggests caution in interpretation of the evolution of bacterial species in terms of evolution of enzyme structure.

The distinction between $M$. avium and $M$. intracellulare is based almost exclusively on agglutinating serotypes and, to a lesser extent, on pathogenicity; Meissner et al. (7) demonstrated marked overlap in almost every other feature studied in their numerical taxonomic analysis of this group. The agglutinating specificity of these organisms appears to reside in the configuration of the oligosaccharide moieties on a common fatty acyl-peptide core of peptidoglycolipid at the cell surface (2). The differences in ImD scores for the catalases from the two serotypes of $M$. avium studied here are only 
slightly less than the differences seen between $M$. avium and $M$. intracellulare and provide no support for maintaining them as separate species.

As a first approximation, the relative divergence of structure of the catalase from the species studied to date appears to be: $M$. scrofula ceum $\leftrightarrow M$. avium $/ M$. intracellulare $\leftrightarrow$ BCG $\leftrightarrow M$. bovis $/ M$. tuberculosis. Any evidence of branching of the train of divergence must await development of more catalase reference sera and study of more species.

\section{ACKNOWLEDGMENTS}

This work was supported by the Medical Research Service of the Veterans Administration.

\section{REPRINT REQUESTS}

Address requests to: Dr. Lawrence G. Wayne, Veterans Administration Hospital, 5901 East Seventh St., Long Beach, CA 90822 .

\section{LITERATURE CITED}

1. Andrejew, A., and Ch. Gernez-Rieux. 1962. Essais de différentiation des mycobactéries d'apres la sensibilité de leur activité catalasique aux inhibiteurs. Ann. Inst. Pasteur (Paris) 103:201-215.

2. Brennan, P. J., and M. B. Goren, 1977. Mycobacterial glycolipids as bacterial antigens. Biochem. Soc. Trans. 5:1687-1694.
3. Cocks, G. T., and A. C. Wilson. 1972. Enzyme evolution in the Enterobacteriaceae. J. Bacteriol. 110:793-802.

4. Diaz, G., and L. G. Wayne. 1974. Isolation and characterization of catalase produced by Mycobacterium tuberculosis. Am. Rev. Respir. Dis. 110:312-319.

5. Kubica, G. P., and G. L. Pool. 1960. Studies on catalase activity of acid-fast bacilli. Am. Rev. Respir. Dis. 81: 387-391.

6. Livingston, D. M. 1974. Immunoaffinity chromatography of proteins. Methods Enzymol. 34:723-730.

7. Meissner, G., K. H. Schröder, G. E. Amadio, W. Anz, S. Chaparas, H. W. B. Engel, P. A. Jenkins, W. Käppler, H. H. Kleeberg, E. Kubala, M. Kubin, D. Lauterbach, A. Lind, M. Magnusson, Zd. Mikova, S. R. Pattyn, W. B. Schaeffer, J. L. Stanford, M. Tsukamura, L. G. Wayne, I. Willers, and E. Wolinsky. 1974. A cooperative numerical analysis of nonscoto- and nonphotochromogenic slowly growing mycobacteria. J. Gen. Microbiol. 83:207-235.

8. Nei, M. 1977. Standard error of immunological dating of evolutionary time. J. Mol. Evol. 9:203-211.

9. Prager, E. M., and A. C. Wilson. 1971. The dependence of immunological cross-reactivity upon sequence resem. blance among lysozymes. J. Biol. Chem. 246:5978-5989.

10. Simpson, D. K., and L. G. Wayne. 1977. Extraction and purification of mycobacterial DNA. Actinomycetes Relat. Organisms 12:36-44.

11. Trudeau Mycobacterial Culture Collection. 1972. Trudeau Mycobacterial Culture Collection catalogue. Trudeau Institute, Inc., Saranac Lake, N.Y.

12. Wayne, L. G., and G. A. Diaz. 1976. Immunoprecipitation studies of mycobacterial catalase. Int. J. Syst. Bacteriol. 26:38-44.

13. Wolinsky, E., and W. B. Schaefer. 1973. Proposed numbering scheme for mycobacterial serotypes by agglutination. Int. J. Syst. Bacteriol. 23:182-183. 